\title{
Establishment and Application of an Evaluation System for the Sustainable Development of Subway Traffic
}

\author{
Dong-Yang Geng ${ }^{1,2, *}$, Karel Vojtasik \\ 1 VŠB-Technical University of Ostrava Faculty of Civil Engineering, ostrava -poruba, buiding E,poruba, \\ 70030 ostrava, Czech Republic; dongyang.geng.st@vsb.cz (D.Y.G.); karel.vojtasik@vsb.cz(D.Y.G.); \\ 2 School of management sclence and engneering Hebei GEO Unibersity shijiahzuang,china \\ * Correspondence: dongyang.geng.st@vsb.cz; Tel.: +420-773-102366
}

\begin{abstract}
According to the characteristics of the sustainable development of subway traffic, the establishment process of an evaluation index system is determined, and the evaluation method and basis are defined. The evaluation index system is established from the aspects of subway traffic sustainability, economic sustainability and urban coordination sustainability. The comprehensive evaluation method of the analytic hierarchy process (AHP) model is used to calculate the weights of comprehensive evaluation indexes at each level. Finally, the sustainable development model of Shijiazhuang subway traffic is evaluated. The results show that the proposed evaluation system and model reflect the degree of sustainable development of subway traffic and can be used for reference in the evaluation of regional subway traffic sustainable development.
\end{abstract}

Keywords: subway traffic; sustainable development; analytic hierarchy process (AHP); evaluation index; index system

\section{Introduction}

Subway traffic is the derivative of urbanization, industrialization and transportation development to a certain stage and focuses on serving urban areas, mainly operating and underground traffic types. Most cities in the world with relatively high levels of motorization have relatively mature and complete subway transportation systems, and some developed cities account for more than half of the traffic volume of urban public transportation[1]. Public transportation plays an extremely important role in the process of urban economic and social operation[2]. However, subway traffic is also facing very large capital pressures, including the failure to recover investments, long-term losses, unsustainable development and other problems[3]. How to realize a balance between the income and expenditures of subway traffic construction and operation to ensure the sustainable development of subway traffic has become a problem that every major city must face[4]. Therefore, it is of great significance in both theory and practice to study the evaluation of the sustainable development of subway traffic.

The traffic research on sustainable development mainly began in the 1990s[5]. "Transport for a Sustainable Society: the Case for Europe," written by John White in 1993, focused on aspects of the influence of urban traffic on the environment, the value of the environment and traffic policy in western European countries[6]. Gary Haq's "Towards Sustainable Transport Planning: A Comparison Between Britain and The Netherlands" in 1997 applied the concept of sustainable development to the practice of urban traffic planning and policy making, which made the 
transportation system more efficient with respect to the economy and the environment[7]. In 1996, the World Bank published a report entitled "Sustainable Transport: Priorities for Policy Reform", which introduced the concept of "sustainable urban transport" and elaborated on the basic contents of three aspects: sustainable development of economics and finance, environmental sustainability and social sustainability[8].

\section{Comprehensive Evaluation Method for Sustainable Development of Subway Traffic}

According to the characteristics of the index system, this paper selects the analytic hierarchy process as the evaluation method for the sustainable development level of subway traffic. The analytic hierarchy process is an effective method to solve multiple objective decision-making problems[9]. Its core idea is to aggregate, refine and decompose the factors related to multiple objective decision making and then transform them into a clear decision-making evaluation model at logical layers, such as the target layer and criterion layer, and thus provide the basis for multiple objective decision making by qualitative information and quantitative methods[10]. The basic idea of the analytic hierarchy process (AHP) is to decompose the target of decision making or evaluation according to the target layer, criterion layer and index layer one by one, and at the same time, to determine the comparative importance of the lower elements to the upper elements one by one and to form the judgment matrix under the element layer[11]. Then, according to the judgment matrix, the weight of the lower elements to the upper elements is determined; next, the decision problem of the target layer is decomposed one by one to the specific index layers[12]. Finally, the whole decision-making evaluation process is finished by quantification from the bottom to the top layer. The steps of the analytical hierarchy process (AHP) are as follows:

First, construct a hierarchical evaluation analysis model[13]. According to the decision-making or evaluation goal, combined with the actual problems, the various factors related to the goal are decomposed one by one from the top to the bottom into the target layer, the criterion layer, the index layer, and so on[14]. A model of hierarchical evaluation and analysis is formed, which is logical and reasonable.

Second, construct a comparison matrix. According to the degree of importance of the hierarchical elements to the target layer[15], the 1-9 scale method proposed by Professor T. L. Saaty is adopted by means of expert scoring, the specific meanings of which are shown in Table 1[16].

Table 1. Scale method

\begin{tabular}{ccccccc}
\hline $\begin{array}{c}\text { Ui vs. uj } \\
\text { importance level }\end{array}$ & $\begin{array}{c}\text { Equally } \\
\text { important }\end{array}$ & $\begin{array}{c}\text { Slightly } \\
\text { important }\end{array}$ & $\begin{array}{c}\text { Obviously } \\
\text { important }\end{array}$ & $\begin{array}{c}\text { Strongly } \\
\text { important }\end{array}$ & $\begin{array}{c}\text { Absolutely } \\
\text { important }\end{array}$ & $\begin{array}{c}\text { Between two } \\
\text { adjacent levels }\end{array}$ \\
\hline Scale & 1 & 3 & 5 & 7 & 9 & $2,4,6,8$ \\
\hline
\end{tabular}

Third, calculate the weights and perform a consistency check. According to the contrast matrix of the lower element to the upper element, by calculating the eigenvector of the maximum eigenvalue of the contrast matrix, the weight vector of the lower element to the upper element is formed[17]. By calculating the average value of each index to express the degree of importance of each index, using EXCEL to determine the relative weight of each index and to perform a consistency check for each index[18], and by judging the matrix consistency ratio by the CR value $(\mathrm{CR}=\mathrm{CI} / \mathrm{RI})[19]$, among which $C I=\left(\lambda_{\max }-n\right) /(n-1)[20]$, the RI values are obtained and shown in Table 2[21]. If $C R<0.1[22]$, the judgment matrix is considered to have good consistency. 
Table 2. Consistency index

\begin{tabular}{lllllllll}
\hline Matrix order number & 3 & 4 & 5 & 6 & 7 & 8 & 9 & 10 \\
\hline RI & 0.52 & 0.89 & 1.12 & 1.26 & 1.36 & 1.41 & 1.46 & 1.49 \\
\hline
\end{tabular}

Fourth, calculate the target score. By quantifying the lowest layer index and combining the weight vector of the lower layer element to the upper layer element[23], calculate the factor score layer by layer from bottom to top; finally, the score of the total target is obtained[24], and the evaluation process is finished. 


\section{The Basis for Comprehensive Evaluation of Sustainable Development of Subway Traffic}

According to the evaluation model and the grading standards of the evaluation index, a comprehensive evaluation for the sustainable development of urban subway traffic is carried out, and the comprehensive evaluation value is calculated by the following formula[25]:

$$
I=\sum_{i=1}^{n} A_{i} \cdot Y_{i}
$$

In the formula, $\mathrm{I}$ is a comprehensive evaluation value, $A_{i}$ is the weight value of the $\mathrm{i}$-th phase index, and $Y_{i}$ is the score of the $\mathrm{i}$-th index[26].

Based on this formula, the comprehensive evaluation value for the sustainable development of urban subway traffic can be calculated, and the degree of development of urban subway traffic can be divided into five levels[27]: very strong sustainable development, strong sustainable development, general sustainable development, weak sustainable development and unsustainable development[28]. Therefore, the basis for sustainable development evaluation is given[29]; see Table 3:

Table 3. Evaluation basis for sustainable development

\begin{tabular}{llllll}
\hline Comprehensive evaluation value & $0 \leq \mathrm{I}<60$ & $60 \leq \mathrm{I}<70$ & $70 \leq \mathrm{I}<80$ & $80 \leq \mathrm{I}<90$ & $90 \leq \mathrm{I}<100$ \\
\hline Degree of sustainable development & None & Weak & General & strong & very strong \\
\hline
\end{tabular}

\section{Construction Process of an Evaluation Index System for Sustainable Development of Subway Traffic}

To make the theory of sustainable development of subway traffic concrete, according to the characteristics of the subway traffic system, it is necessary to describe the subway traffic system with different indexes from different aspects and then evaluate the sustainable development of subway traffic[30]. These different evaluation indexes constitute the evaluation index system for the sustainable development of subway traffic[31]. The process of establishing the evaluation index system for the sustainable development of subway traffic is shown in Fig. 1. 


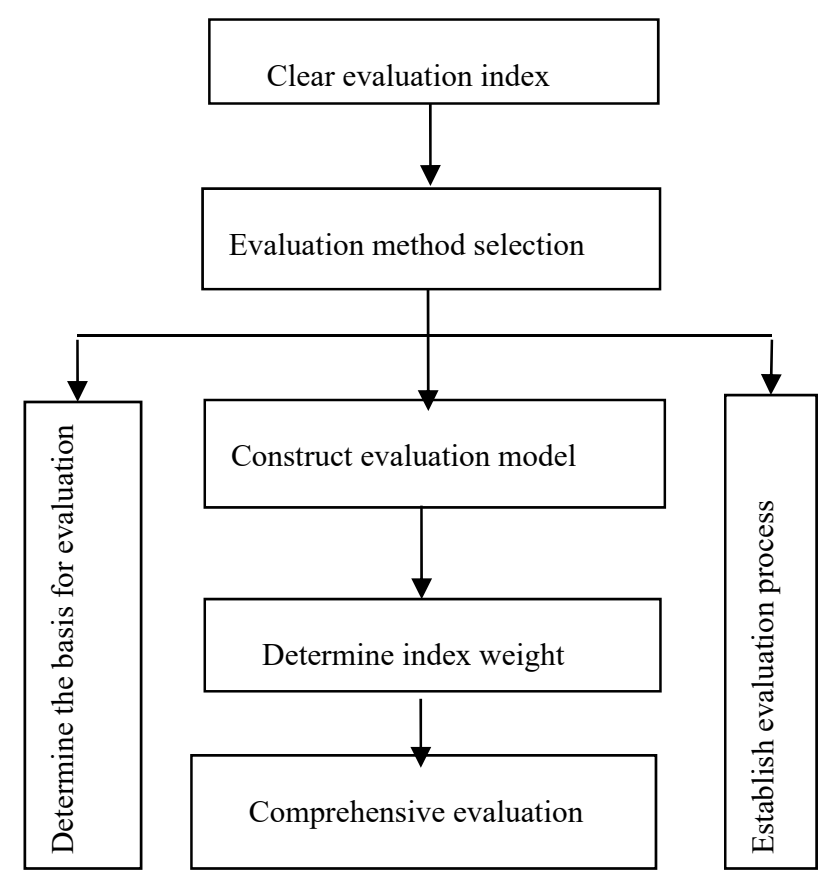

Fig. 1 Evaluation index system establishment process

\section{Construction of Evaluation Index System for Sustainable Development of Subway Traffic}

The evaluation system for the sustainable development of subway traffic adopts the tower structure with the commonly used layer number analysis method; the top layer is the evaluation target[32], that is, the evaluation of the sustainable development of urban subway traffic, the second layer contains some evaluation criteria, and the third layer is the index layer.

\subsection{First level index}

Starting from the interests of the government, users and developers in the main operation body of subway traffic development and combining these interests with the connotation and requirements for the sustainable development of subway traffic[33-34], the index for determining the criteria layer mainly includes the following three aspects.

Traffic sustainability $\left(\mathrm{u}_{1}\right)$. As one kind of urban traffic, urban subway traffic should meet the basic traffic demands of urban development and have certain social benefits[35]. For users, the residents should be provided with safe, comfortable and efficient transportation methods[36]; for operators, subway traffic should have a high passenger traffic capacity[37]; for the government, subway traffic should have reasonable coverage.

Economic sustainability $\left(\mathrm{u}_{2}\right)$. To realize the sustainable development of the economy of urban subway traffic[38], the investor government of the subway traffic project must realize the balance of revenues and expenditures between the construction and operation of subway traffic[39].

Urban coordination sustainability $\left(\mathrm{u}_{3}\right)$. The fundamental goal of urban subway transportation as a means of transportation is to achieve sustainable urban development, so it is necessary to coordinate urban development[40], mainly including the coordination of the urban subway transportation and other modes of transportation, [41]coordination with surrounding land use and urban development, and coordination of landscapes and historical landscapes.

In general, the evaluation of the ability to achieve the sustainable development of urban subway traffic mainly includes two aspects: one aspect is to pay attention to the development state, 
which requires not only the equilibrium of the internal structure of the urban subway traffic at a specific stage of development but also the coordination of all features of urban subway traffic and urban development and the optimality of overall benefit; the second aspect is to pay attention to the dynamic development process through the rational use and allocation of traffic resources, to provide adequate basic support for subway traffic in each stage of the development, and to ensure the continuity and stability of the development process.

\subsection{Second level index}

For the refinement of the criteria layer, set a third layer of indicator layers that are more specific and easier to operate[42]. In the initial selection of the sustainable development of urban subway traffic evaluation index layer indicators, the traffic sustainability $\left(\mathrm{u}_{1}\right)$ index layer can be selected as the average bus travel time savings, transfer and convergence, subway traffic volume accounting for a proportion of public transport total passenger traffic volume, site coverage rate, total length of the network, and the nonlinear coefficients of the line network, transfer and convergence. The index layer of economic sustainability $\left(\mathrm{u}_{2}\right)$ is chosen as the annual operating income, land appreciation benefit rate, annual operating cost, improvement of labor productivity efficiency, coordination coefficient of subway transportation investment, input-output ratio and rate of return. The index layer of urban coordination sustainability $\left(\mathrm{u}_{3}\right)$ is chosen as coordination with land use, coordination with urban planning and development, connectivity rate of main distribution points, coordination with the urban environment and historical landscape, promotion of urban district development, improvement of the urban environment quality and coordination with other transportation modes.

\section{Use AHP to determine index level indicators}

Using the AHP indicator screening method, the comparison matrix is constructed using the 1-9 scale method. Seven indicators are selected under traffic sustainability, represented by $\mathrm{u}_{11}, \mathrm{u}_{12}, \mathrm{u}_{13}, \mathrm{u}_{14}, \mathrm{u}_{15}, \mathrm{u}_{16}, \mathrm{u}_{17}$, and the comparison matrix $\mathrm{C}$ matrix is as follows.

$$
\mathrm{C}=\left[\begin{array}{lllllll}
1 & 1 & 1 & 0 & 2 & 2 & 1 \\
1 & 1 & 1 & 0 & 2 & 2 & 1 \\
1 & 1 & 1 & 0 & 2 & 2 & 1 \\
2 & 2 & 2 & 1 & 2 & 2 & 1 \\
0 & 0 & 0 & 0 & 1 & 0 & 0 \\
0 & 0 & 0 & 0 & 2 & 1 & 0 \\
1 & 1 & 1 & 1 & 2 & 2 & 1
\end{array}\right]
$$

According to the calculation method of index weight in the AHP method, the importance ranking of indicators under the traffic sustainability criterion layer can be obtained. $\mathrm{W}=$ $\left(\mathrm{u}_{11}, \mathrm{u}_{12}, \mathrm{u}_{13}, \mathrm{u}_{14}, \mathrm{u}_{15}, \mathrm{u}_{16}, \mathrm{u}_{17}\right)$, so the value of the index weight is $\mathrm{W}=(0.144,0.144,0.144,0.456$, $0.021,0.028,0.159)$.

According to the scale method, the order is as follows: the travel time is improved $\left(\mathrm{u}_{14}\right)>$ the transfer and convergence $\left(\mathrm{u}_{17}\right)>$ the proportion of subway traffic volume to the total amount of public transportation, the station coverage rate, the total length of the line network $\left(\mathrm{u}_{11}, \mathrm{u}_{12}, \mathrm{u}_{13}\right)>$ nonlinear coefficient of the line network $\left(\mathrm{u}_{16}\right)>$ transfer and convergence $\left(\mathrm{u}_{15}\right)$. At the same time, considering that the total length of the line network varies with the size of the city, the economy, etc., the line network is subjective and can be more objectively described through site coverage, taking travel time savings, transfer and convergence, and subway traffic volume in public transport proportion, and site coverage rate as the lower level index of the traffic sustainability criteria layer. 
In the same way, the order of importance of the lower-level indicators of the two levels of economic sustainability and urban coordination sustainability can be obtained[43]. According to the principle of establishing the index system, the following complete indicator models are obtained[44], as shown in Table 4.

Table 4. Comprehensive evaluation index model for the sustainable development of subway traffic

\begin{tabular}{|c|c|c|}
\hline Target layer & Criteria layer & Index layer \\
\hline \multirow{11}{*}{$\begin{array}{l}\text { Evaluation of } \\
\text { the } \\
\text { sustainable } \\
\text { development } \\
\text { of subway } \\
\text { traffic }\end{array}$} & \multirow{5}{*}{ Traffic sustainability $B_{1}$} & Travel time improvement $C_{1}$ \\
\hline & & Transfer and convergence $C_{2}$ \\
\hline & & Subway share rate $C_{3}$ \\
\hline & & Subway station coverage rate $C_{4}$ \\
\hline & & $\begin{array}{l}\text { Coordination coefficient of subway traffic } \\
\text { investment } C_{5}\end{array}$ \\
\hline & \multirow{3}{*}{ Economic sustainability $\mathrm{B}_{2}$} & Annual operating cost $C_{6}$ \\
\hline & & Annual operating income $\mathrm{C}_{7}$ \\
\hline & & Added-value rate of surrounding land $C_{8}$ \\
\hline & \multirow[t]{3}{*}{ Urban coordination sustainability $B_{3}$} & Coordination with other transportation $\mathrm{C}_{9}$ \\
\hline & & Coordination with land development $\mathrm{C}_{10}$ \\
\hline & & Coordination with urban environment $C_{11}$ \\
\hline
\end{tabular}

\section{Determination of the Weight of the Comprehensive Evaluation Index in Each Layer}

7.1 The weight of each indicator in the indicator layer

For the weight vector $\mathrm{w}_{\mathrm{B} 1}$ of the four indicators of traffic sustainability, the solution process is as follows[45]:

First, combined with the expert consultation method, and the scale method is used to establish a complementary fuzzy judgment matrix F[46]:

$$
\mathrm{F}=\left(\mathrm{f}_{\mathrm{ij}}\right)_{\mathrm{m} \times \mathrm{n}}=\left[\begin{array}{llll}
0.5 & 1.0 & 0.0 & 0.0 \\
0.0 & 0.5 & 0.0 & 0.0 \\
1.0 & 1.0 & 0.5 & 0.5 \\
1.0 & 0.5 & 0.5 & 0.5
\end{array}\right]
$$

Reuse the conversion formula $e_{i j}=\frac{r_{i j}}{r_{j i}}$ and change $R=\left(r_{i j}\right)_{m \times n}$ to obtain the inversion matrix $\mathrm{E}=\left(\mathrm{e}_{\mathrm{ij}}\right)_{\mathrm{m} \times \mathrm{n}}[47]$.

$$
E=\left(e_{i j}\right)_{m \times n}=\left[\begin{array}{llll}
1.000 & 1.679 & 0.488 & 0.623 \\
0.591 & 1.000 & 0.245 & 0.344 \\
2.119 & 4.333 & 1.102 & 1.279 \\
1.567 & 3.000 & 0.767 & 1.000
\end{array}\right]
$$


Using the sort vector $\mathrm{w}^{(0)}$ as the iterative initial value $\mathrm{V}_{0}$ of the eigenvalue method, after successive iterations[48], $\left\|V_{k+1}\right\|_{\infty}-\left\|V_{k}\right\|_{\infty}<0.001$ [49]can be obtained. Then, the sort vector $w^{(3)}$ at this time is the weight vector $\mathrm{w}_{\mathrm{B} 1}$, and the $\mathrm{w}_{\mathrm{B} 1}$ value is $(0.174,0.137,0.329,0.322)^{\mathrm{T}}$, that is, for the traffic sustainability of the four indicators using the improved analytic hierarchy process (AHP) to determine the weight[50].

In the same way, the weights $\mathrm{w}_{\mathrm{B} 3}=(0.213,0.213,0.213,0.318)^{\mathrm{T}}$ determined by the improved fuzzy analytic hierarchy process (FAHP) for the four indicators of economic sustainability can be obtained. The three indicators of urban coordination use the weight $\mathrm{w}_{\mathrm{B} 3}=$ $(0.2916 .0 .445 .0 .239)^{\mathrm{T}}$ determined by the analytic hierarchy process (AHP).

\subsection{Index weight in the criteria layer}

Using the same method as above, the weight of the criterion index system for the sustainable comprehensive evaluation of urban subway traffic is $\mathrm{w}_{\mathrm{A}}=(0.34,0.34,0.35)^{\mathrm{T}}$. Therefore, the weight coefficient of the comprehensive evaluation index system is the product of the corresponding criteria layer weight $\mathrm{w}_{\mathrm{A}}$ and the index layer weight $\left(\mathrm{w}_{\mathrm{B} 1}, \mathrm{w}_{\mathrm{B} 2}, \mathrm{w}_{\mathrm{B} 3}\right)$.

\section{Evaluation of the sustainable development model for subway traffic in Shijiazhuang City}

According to the index of correlation in the evaluation index system of sustainable traffic development in Hebei Province[51], the evaluation of the sustainable development level of subway transportation in Shijiazhuang City is made. See Table 5.

Table 5. Comprehensive evaluation index standards for sustainable development of subway traffic in large cities

\begin{tabular}{cccccc}
\hline Score & $\mathbf{0 - 6 0}$ & $\mathbf{6 0 - 7 0}$ & $\mathbf{7 0 - 8 0}$ & $\mathbf{8 0 - 9 0}$ & $\mathbf{9 0 - 1 0 0}$ \\
\hline $\mathrm{C}_{1}$ & $<15$ & $15-35$ & $35-45$ & $45-55$ & $>55$ \\
$\mathrm{C}_{2}$ & $>1.6$ & $1.5-1.6$ & $1.4-1.5$ & $1.3-1.2$ & $<1.2$ \\
$\mathrm{C}_{3}$ & $<15$ & $15-30$ & $30-40$ & $40-50$ & $>50$ \\
$\mathrm{C}_{4}$ & $<20$ & $20-40$ & $40-50$ & $50-60$ & $>60$ \\
$\mathrm{C}_{5}$ & $>9$ & $5-9$ & $3-5$ & $2-3$ & $1-2$ \\
$\mathrm{C}_{6}$ & $>60$ & $30-60$ & $30-60$ & $20-30$ & $<10$ \\
$\mathrm{C}_{7}$ & $<10$ & $10-20$ & $20-25$ & $25-30$ & $>50$ \\
$\mathrm{C}_{8}$ & $<10$ & $10-20$ & $20-25$ & $25-30$ & $>30$ \\
$\mathrm{C}_{9}$ & Poor & Worse & General & Relatively & Good \\
& & & & Good \\
$\mathrm{C}_{10}$ & Poor & Worse & General & good & Good \\
& & & & Relatively & Good \\
$\mathrm{C}_{11}$ & Poor & Worse & General & good & \\
\hline
\end{tabular}


Indicator status value and score: According to the evaluation criteria of the above single index and the statistical data for the present situation of subway traffic, the score of each single index is calculated, and the weight of each index is calculated. According to formula (1), the comprehensive evaluation value of sustainable development for the present situation of the urban subway traffic system is calculated. The results are shown in Table 6.

Table 6. Comprehensive evaluation index score

\begin{tabular}{lclll}
\hline Score & $\begin{array}{c}\text { Current status } \\
\text { value }\end{array}$ & Score & Weight & Weighted score \\
\hline $\mathrm{C}_{1}$ & 39.5 & 81.8 & 0.0629 & 5.1364 \\
$\mathrm{C}_{2}$ & 1.29 & 83 & 0.0461 & 3.7998 \\
$\mathrm{C}_{3}$ & 45 & 81 & 0.1176 & 9.7980 \\
$\mathrm{C}_{4}$ & 44.3 & 73.9 & 0.1034 & 7.7981 \\
$\mathrm{C}_{5}$ & 4.6 & 74.9 & 0.0747 & 5.4876 \\
$\mathrm{C}_{6}$ & 46 & 61 & 0.0729 & 4.9854 \\
$\mathrm{C}_{7}$ & 48 & 84 & 0.0747 & 6.5123 \\
$\mathrm{C}_{8}$ & 29 & 88 & 0.1077 & 9.4001 \\
$\mathrm{C}_{9}$ & Relatively good & 86 & 0.1084 & 9.4322 \\
$\mathrm{C}_{10}$ & Relatively good & 82 & 0.1473 & 11.9989 \\
$\mathrm{C}_{11}$ & Relatively good & 85 & 0.0843 & 6.9913 \\
Total & & & 1 & 81.34 \\
\hline
\end{tabular}

According to the calculation, the comprehensive evaluation value of the sustainable development of subway traffic in Shijiazhuang City is 81.34. According to the criterion of the degree of sustainable development, the development level of subway traffic in Shijiazhuang City shows very strong sustainable development. From the viewpoint of the index score, the scoring rate of the operating cost index is lower than $70 \%$, and the subway station coverage rate and the coordination coefficient of subway traffic investment are lower than $80 \%$. From the evaluation results, in order to further promote the sustainable development of urban subway traffic, we should actively adopt new technology, innovate management modes, focus on controlling operating costs, and at the same time attach importance to strengthening the sustainable construction capacity of subway traffic and improving the service level and radiation capacity of subway traffic.

\section{Conclusions and Discussion}

According to the characteristics of the sustainable development of subway traffic evaluation, an evaluation index system flow is established, and the purpose of evaluation is clarified. The subway traffic sustainability, economic sustainability and urban coordination sustainability are evaluated.

The evaluation index system model is established, and the comprehensive evaluation method of the AHP model is adopted to achieve the purpose of evaluating the sustainable development of subway traffic. 
The results of a case analysis show that through this evaluation index system and model, the purpose of sustainable development evaluation of subway traffic can be achieved, and the degree of sustainable development of subway traffic among regions can be compared.

Author Contributions: D.Y.G. and K.V. designed the framework of the research; D.Y.G. collected the data; D.-Y.G. and K.V.. analyzed and interpreted the data; D.Y.G. and K.V. prepared a draft of the article; D.Y.G. and K.V reviewed and edited the draft.

Funding: This research was funded by the Social Science Fund Project in Hebei Provincial of China (HB18YJ015)

Acknowledgments: The authors are grateful to editors and anonymous referees for their very valuable comments and suggestions, which significantly helped improve the quality of this paper.

Conflicts of Interest: The authors declare no conflicts of interest.

\section{References}

1. Beiler, M.; Treat, C., Integrating GIS and AHP to Prioritize Transportation Infrastructure Using Sustainability Metrics. Journal of Infrastructure Systems 2015, 21 (3). DOI: 10.1061/(ASCE)IS.1943-555X.0000245.

2. Benenson, I.; Ben-Elia, E.; Rofe, Y.; Geyzersky, D., The benefits of a high-resolution analysis of transit accessibility. International Journal of Geographical Information Science 2017, 31 (2), 213-236. DOI: 10.1080/13658816.2016.1191637.

3. Beng, S.; Matsumoto, T., Survival analysis on bridges for modeling bridge replacement and evaluating bridge performance. Structure and Infrastructure Engineering 2012, 8 (3), 251-268. DOI: 10.1080/15732471003594393.

4. Casas, J.; Wisniewski, D., Safety requirements and probabilistic models of resistance in the assessment of existing railway bridges. Structure and Infrastructure Engineering 2013, 9 (6), 529-545. DOI: 10.1080/15732479.2011.581673.

5. d'Orey, P.; Ferreira, M., ITS for Sustainable Mobility: A Survey on Applications and Impact Assessment Tools. Ieee Transactions on Intelligent Transportation Systems 2014, 15 (2), 477-493. DOI: 10.1109/TITS.2013.2287257.

6. de la Fuente, A.; Blanco, A.; Armengou, J.; Aguado, A., Sustainability based-approach to determine the concrete type and reinforcement configuration of TBM tunnels linings. Case study: Extension line to Barcelona Airport T1. Tunnelling and Underground Space Technology 2017, 61, 179-188. DOI: 10.1016/j.tust.2016.10.008.

7. Dong, J.; Hu, W.; Yan, S.; Ren, R.; Zhao, X., Network Planning Method for Capacitated Metro-Based Underground Logistics System. Advances in Civil Engineering 2018. DOI: 10.1155/2018/6958086.

8. Duell, M.; Gardner, L.; Waller, S., Policy implications of incorporating distance constrained electric vehicles into the traffic network design problem. Transportation Letters-the International Journal of Transportation Research 2018, 10 (3), 144-158. DOI: 10.1080/19427867.2016.1239306. 
9. Erdil, A., An Overview of Sustainability of Transportation Systems: A Quality Oriented Approach. Tehnicki Vjesnik-Technical Gazette 2018, 25, 343-353. DOI: 10.17559/TV-20170618125022.

10. Fang, C.; Luo, K.; Kong, Y.; Lin, H.; Ren, Y., Evaluating Performance and Elucidating the Mechanisms of Collaborative Development within the Beijing-Tianjin-Hebei Region, China. Sustainability 2018, 10 (2). DOI: $10.3390 /$ su10020471.

11. Farid, Y.; Christofa, E.; Collura, J., An analytical model to conduct a person-based evaluation of transit preferential treatments on signalized arterials. Transportation Research Part C-Emerging Technologies 2018, 90, 411-432. DOI: 10.1016/j.trc.2017.12.010.

12. Fontes, T.; Fernandes, P.; Rodrigues, H.; Bandeira, J.; Pereira, S.; Khattak, A.; Coelho, M., Are HOV/eco-lanes a sustainable option to reducing emissions in a medium-sized European city? Transportation Research Part a-Policy and Practice 2014, 63, 93-106. DOI: 10.1016/j.tra.2014.03.002.

13. Gori, S.; La Spada, S.; Mannini, L.; Nigro, M., Emission dynamic meso-simulation model to evaluate traffic strategies in congested urban networks. Iet Intelligent Transport Systems 2015, 9 (3), 333-342. DOI: 10.1049/iet-its.2013.0026.

14. Griskeviciute-Geciene, A., THE EVALUATION OF INVESTMENT PROJECTS WITHIN THE TERRITORY OF DEVELOPMENT. Transport 2010, 25 (2), 203-214. DOI: 10.3846/transport.2010.25.

15. Joumard, R.; Nicolas, J., Transport project assessment methodology within the framework of sustainable development. Ecological Indicators 2010, 10 (2), 136-142. DOI: 10.1016/j.ecolind.2009.04.002.

16. Kang, C.; Khan, H.; Feng, C.; Wu, C., Efficiency evaluation of bus transit firms with and without consideration of environmental air-pollution emissions. Transportation Research Part D-Transport and Environment 2017, 50, 505-519. DOI: 10.1016/j.trd.2016.10.012.

17. Khan, N.; Habib, M., Evaluation of Preferences for Alternative Transportation Services and Loyalty towards Active Transportation during a Major Transportation Infrastructure Disruption. Sustainability 2018, 10 (6). DOI: 10.3390/su10062050.

18. Kolak, O.; Feyzioglu, O.; Birbil, S.; Noyan, N.; Yalcindag, S., USING EMISSION FUNCTIONS IN MODELING ENVIRONMENTALLY SUSTAINABLE TRAFFIC ASSIGNMENT POLICIES. Journal of Industrial and Management Optimization 2013, 9 (2), 341-363. DOI: 10.3934/jimo.2013.9.341.

19. Krmac, E.; Djordjevic, B., An evaluation of train control information systems for sustainable railway using the analytic hierarchy process (AHP) model. European Transport Research Review 2017, 9 (3). DOI: 10.1007/s12544-017-0253-9.

20. Lee, J.; Boarnet, M.; Houston, D.; Nixon, H.; Spears, S., Changes in Service and Associated Ridership Impacts near a New Light Rail Transit Line. Sustainability 2017, 9 (10). DOI: 10.3390/su9101827.

21. Lee, J.; Park, B.; Malakorn, K.; So, J., Sustainability assessments of cooperative vehicle intersection control at an urban corridor. Transportation Research Part C-Emerging Technologies 2013, 32, 193-206. DOI: 10.1016/j.trc.2012.09.004.

22. Li, X.; Li, C.; Aurele, P.; Wu, W.; Li, H.; Sun, L.; Liu, C., Multiple resources and their sustainable development in Urban Underground Space. Tunnelling and Underground Space Technology 2016, 55, 59-66. DOI: 10.1016/j.tust.2016.02.003.

23. Lin, W.; Li, Y.; Li, X.; Xu, D., The dynamic analysis and evaluation on tourist ecological footprint of city: Take Shanghai as an instance. Sustainable Cities and Society 2018, 37, 541-549. DOI: 10.1016/j.scs.2017.12.003.

24. Liu, K.; Chan, E.; Lee, V.; Kapitanova, K.; Son, S., Design and evaluation of token-based reservation for a roadway system. Transportation Research Part C-Emerging Technologies 2013, 26, 184-202. DOI: 10.1016/j.trc.2012.09.001. 
25. Lopez, J.; Grindlay, A.; Pena-Garcia, A., A proposal for evaluation of energy consumption and sustainability of road tunnels: The sustainability vector. Tunnelling and Underground Space Technology 2017, 65, 53-61. DOI: 10.1016/j.tust.2017.02.008.

26. Lowson, M., Sustainable personal transport. Proceedings of the Institution of Civil Engineers-Municipal Engineer 2002, 151 (1), 73-81.

27. Lu, S.; Liu, Y., Evaluation system for the sustainable development of urban transportation and ecological environment based on SVM. Journal of Intelligent \& Fuzzy Systems 2018, 34 (2), 831-838. DOI: 10.3233/JIFS-169376.

28. Meng, F.; Liu, G.; Yang, Z.; Casazza, M.; Cui, S.; Ulgiati, S., Energy efficiency of urban transportation system in Xiamen, China. An integrated approach. Applied Energy 2017, 186, 234-248. DOI: 10.1016/j.apenergy.2016.02.055.

29. Meng, F.; Liu, G.; Yang, Z.; Casazza, M.; Cui, S.; Ulgiati, S., Energy efficiency of urban transportation system in Xiamen, China. An integrated approach. Applied Energy 2017, 186, 234-248. DOI: 10.1016/j.apenergy.2016.02.055.

30. Papatzikou, E.; Stathopoulos, A., An optimization method for sustainable traffic control in urban areas. Transportation Research Part C-Emerging Technologies 2015, 55, 179-190. DOI: 10.1016/j.trc.2015.02.006.

31. Penttala, V., Concrete and sustainable development. Aci Materials Journal 1997, 94 (5), 409-416.

32. Pijoan, A.; Kamara-Esteban, O.; Alonso-Vicario, A.; Borges, C., Transport Choice Modeling for the Evaluation of New Transport Policies. Sustainability 2018, 10 (4). DOI: 10.3390/su10041230.

33. Qin, J.; He, Y.; Ni, L., Quantitative Efficiency Evaluation Method for Transportation Networks. Sustainability 2014, 6 (12), 8364-8378. DOI: 10.3390/su6128364.

34. Rossi, R.; Gastaldi, M.; Gecchele, G., Comparison of fuzzy-based and AHP methods in sustainability evaluation: a case of traffic pollution-reducing policies. European Transport Research Review 2013, 5 (1), 11-26. DOI: 10.1007/s12544-012-0086-5.

35. Sarmiento, S.; Spadaro, S.; Lazaro, J., Cost-effective ROADM design to maximize the Traffic Load Capacity of u-DWDM coherent metro-access networks. Optical Switching and Networking 2018, 30, 53-61. DOI: 10.1016/j.osn.2018.06.002.

36. Shiau, T.; Liu, J., Developing an indicator system for local governments to evaluate transport sustainability strategies. Ecological Indicators 2013, 34, 361-371. DOI: 10.1016/j.ecolind.2013.06.001.

37. Shiau, T.; Liu, J., Developing an indicator system for local governments to evaluate transport sustainability strategies. Ecological Indicators 2013, 34, 361-371. DOI: 10.1016/j.ecolind.2013.06.001.

38. Shirgaokar, M.; Deakin, E.; Duduta, N., Integrating Building Energy Efficiency with Land Use and Transportation Planning in Jinan, China. Energies 2013, 6 (2), 646-661. DOI: 10.3390/en6020646.

39. Shirgaokar, M.; Deakin, E.; Duduta, N., Integrating Building Energy Efficiency with Land Use and Transportation Planning in Jinan, China. Energies 2013, 6 (2), 646-661. DOI: 10.3390/en6020646.

40. Sivilevicius, H.; Paliulis, G.; Klibavicius, A.; Palevicius, V., RESEARCH ON THE OPERATION OF ROUNDABOUTS BASED ON THE SUSTAINABLE DEVELOPMENT PRINCIPLES. Baltic Journal of Road and Bridge Engineering 2015, 10 (2), 166-173. DOI: 10.3846/bjrbe.2015.21.

41. Srinivasan, K.; Naidu, G.; Sutrala, T., Heterogeneous Decision Rule Model of Mode Choice Incorporating Utility Maximization and Disutility Minimization. Transportation Research Record 2009, (2132), 59-68. DOI: 10.3141/2132-07.

42. Stamos, I.; Triantafyllos, D., BUS RAPID TRANSIT AS A CONTRIBUTION TO SUSTAINABLE TRANSPORTATION. THE CASE OF ATHENS, GREECE. Journal of Environmental Protection and Ecology 2012, 13 (2), 611-619. 
43. Thekdi, S.; Lambert, J., Integrated risk management of safety and development on transportation corridors. Reliability Engineering \& System Safety 2015, 138, 1-12. DOI: 10.1016/j.ress.2014.11.015.

44. VanWee, B., The treatment of traffic in the Dutch environmental outlooks: The role of science in policy making and policy evaluation. Transportation Planning and Technology 1996, 19 (3-4), 265-274. DOI: 10.1080/03081069608717573.

45. Vermote, L.; Macharis, C.; Hollevoet, J.; Putman, K., Participatory evaluation of regional light rail scenarios: A Flemish case on sustainable mobility and land-use. Environmental Science \& Policy 2014, 37, 101-120. DOI: 10.1016/j.envsci.2013.08.013.

46. Weng, J.; Di, X.; Wang, C.; Wang, J.; Mao, L., A Bus Service Evaluation Method from Passenger's Perspective Based on Satisfaction Surveys: A Case Study of Beijing, China. Sustainability 2018, 10 (8). DOI: $10.3390 /$ su10082723.

47. Wu, J.; Zhu, Q.; Chu, J.; Liu, H.; Liang, L., Measuring energy and environmental efficiency of transportation systems in China based on a parallel DEA approach. Transportation Research Part D-Transport and Environment 2016, 48, 460-472. DOI: 10.1016/j.trd.2015.08.001.

48. Xu, Y.; Tang, T.; Sun, G., Research on planning evaluation index system of residential areas in mountainous city for geological disaster prevention-A case. Disaster Advances 2013, 6, 114-121.

49. Yang, Y.; Liu, Y.; Zhou, M.; Li, F.; Sun, C., Robustness assessment of urban rail transit based on complex network theory: A case study of the Beijing Subway. Safety Science 2015, 79, 149-162. DOI: 10.1016/j.ssci.2015.06.006.

50. Yang, Y.; Lu, H.; Yin, Y.; Yang, H., Optimization of Variable Speed Limits for Efficient, Safe, and Sustainable Mobility. Transportation Research Record 2013, (2333), 37-45. DOI: 10.3141/2333-05.

51. Zhang, X.; Chen, Y.; Li, M., Research on Geospatial Association of the Urban Agglomeration around the South China Sea Based on Marine Traffic Flow. Sustainability 2018, 10 (9). DOI: 10.3390/su10093346. 